\title{
Altered Wound Healing in Mice Lacking a Functional Osteopontin Gene (spp1)
}

Lucy Liaw, ${ }^{\star}$ David E. Birk, $\|$ Christopher B. Ballas, ${ }^{\S}$ Jeffrey S. Whitsitt, ${ }^{\S}$ Jeffrey M. Davidson, ${ }^{\S \uparrow}$ and Brigid L.M. Hogan ${ }^{\star \ddagger}$

$*$ Department of Cell Biology and ${ }^{\ddagger}$ Howard Hughes Medical Institute, ${ }^{\S}$ Department of Pathology, Vanderbilt University Medical Center, Nashville, Tennessee 37232; "Department of Anatomy and Cellular Biology, Tufts University School of Medicine, Boston, Massachusetts 02111; and "Department of Veterans Affairs Medical Center, Nashville, Tennessee 37212-2637

\begin{abstract}
Osteopontin (OPN) is an arginine-glycine-aspartate (RGD)containing glycoprotein encoded by the gene secreted phosphoprotein 1 (spp1). spp1 is expressed during embryogenesis, wound healing, and tumorigenesis; however, its in vivo functions are not well understood. Therefore, OPN null mutant mice were generated by targeted mutagenesis in embryonic stem cells. In OPN mutant mice, embryogenesis occurred normally, and mice were fertile. Since OPN shares receptors with vitronectin (VN), we tested for compensation by creating mice lacking both OPN and VN. The double mutants were also viable, suggesting that other RGD-containing ligands replace the embryonic loss of both proteins. We tested the healing of OPN mutants after skin incisions, where spp1 was upregulated as early as $6 \mathrm{~h}$ after wounding. Although the tensile properties of the wounds were unchanged, ultrastructural analysis showed a significantly decreased level of debridement, greater disorganization of matrix, and an alteration of collagen fibrillogenesis leading to small diameter collagen fibrils in the OPN mutant mice. These data indicate a role for OPN in tissue remodeling in vivo, and suggest physiological functions during matrix reorganization after injury. (J. Clin. Invest. 1998. 101:14681478.) Key words: gene targeting • matrix • vitronectin • collagen • skin
\end{abstract}

\section{Introduction}

Osteopontin $(\mathrm{OPN})^{1}$ is a secreted phosphoprotein containing the arginine-glycine-aspartate (RGD) tripeptide integrin binding motif. Early isolation of OPN from bone (1) and subsequent cloning (2) indicated a function in the adhesion of bone cells to the mineralized matrix. However, the gene encoding OPN was soon found to be identical to a gene induced upon

Address correspondence to Lucy Liaw, Center for Molecular Medicine, Maine Medical Center Research Institute, 125 John Roberts Rd., Suite \#8, South Portland, ME 04106. Phone: 207-761-9090; FAX: 207-761-2130; E-mail: liawl@poa.mmc.org

Received for publication 25 October 1997 and accepted in revised form 26 January 1998.

1. Abbreviations used in this paper: ES, embryonic stem; HPRT, hypoxanthine phosphoribosyltransferase; MEF, mouse embryonic fibroblasts; neo ${ }^{r}$, neomycin resistance; OPN, osteopontin; PGK, phosphoglycerokinase; RGD, arginine-glycine-aspartate; RT, reverse transcription; spp1, secreted phosphoprotein 1 gene; VN, vitronectin.

The Journal of Clinical Investigation Volume 101, Number 7, April 1998, 1468-1478

http://www.jci.org cell transformation $(3,4)$, and later was shown to have a more widespread distribution, suggesting relevance in other tissues as well. The gene was also independently described as etal, a $\mathrm{T}$ cell product induced after cell activation (5). Further work related to immune cell function has provided evidence that OPN acts as a cytokine, and may play important roles in $\mathrm{T}$ cell and macrophage function during responses to bacterial infection, pathogen resistance, and wound healing (6). In vitro studies using purified protein have verified that OPN can act as an adhesion substrate and migration stimulus by interaction with several integrins, leading to downstream signaling events that include calcium mobilization, protein phosphorylation, and regulation of gene expression and cell differentiation (7).

A variety of studies have shown that the gene secreted phosphoprotein 1 (spp1) is expressed in selected tissues during embryonic development. Transcripts for sppl are first detectable during gastrulation in the notochord (8). Secreted factors from the notochord are known to affect neural and somitic cell differentiation (9), raising the possibility that OPN contributes to notochord elongation or sclerotomal cell migration. The second region of high sppl expression is at the embryonic/maternal interface. OPN is produced by invading trophoblasts, by the metrial gland cells of the deciduum, and in the placenta (10), correlating temporally with blastocyst invasion and later, placentation. Experiments addressing the functions of OPN during embryogenesis have not been described previously.

Of note, another RGD-containing protein, vitronectin (VN), has been localized during embryonic development to regions overlapping with sppl expression. Although limited in sites of synthesis primarily to hepatocytes and some areas of the central nervous system, circulating plasma levels of VN are on the order of $200-400 \mu \mathrm{g} / \mathrm{ml}$, and deposition of the protein occurs in several tissues (11). As a consequence, embryonic tissues, including the notochord, placenta, deciduum, and some connective tissues, both produce OPN and are sites of VN deposition (12). Targeted mutation of the gene encoding VN, vtn, has demonstrated that normal embryonic development occurs in the absence of VN protein (13). Therefore, we were interested in the interactions of $\mathrm{VN}$ and OPN during embryogenesis.

To address the in vivo roles of OPN, we have generated a null mutation in the murine sppl gene by homologous recombination in embryonic stem (ES) cells. We report that the loss of OPN or both OPN and VN is permissive for embryonic development, and the OPN mutants as well as OPN/VN double mutants were also fertile. These observations suggest that additional RGD-containing proteins may be acting in a compensatory manner. The viability of the OPN mutant allows us to address the roles of this protein in the adult, where despite numerous studies, its in vivo roles are not well established.

In the adult, OPN production is normally restricted, but upregulation of sppl occurs during cell injury and pathology. sppl is highly expressed in transformed cells, and OPN is found in a variety of tumors (14). The presence of OPN at sites 
of wound healing, particularly associated with leukocytes (15, $16)$, is concordant with a model where OPN is an important effector of the immune response. The necessity of a robust immune response for subsequent healing has been demonstrated by macrophage depletion studies (17) and stimulation of macrophages using immunomodulators (18). A postulated role for OPN at wound sites is to function as a mediator of immune cell function and subsequent repair. Paradigms of tissue injury associated with spp1 upregulation are as diverse as cardiovascular injury and disease (19), renal tubulointerstitial fibrosis (20), and kidney stone formation (21).

Using full-thickness skin incisions to study immune cell function and wound matrix remodeling, we report significant differences in the ability of OPN mutant animals to remodel wound matrix in a process that involves fibrillar collagen organization. Thus, our studies demonstrate the novel findings that mice lacking OPN and VN develop normally and are fertile, and that OPN functions during dermal tissue repair and collagen fibrillogenesis.

\section{Methods}

\section{Construction of spp1 targeting vector}

A $129 /$ SvJ genomic library (Stratagene, Inc., La Jolla, CA) was screened using a 3' 196-bp fragment of the spp1 cDNA. Two of the largest positive clones were characterized by restriction and partial sequence analysis. The replacement targeting vector was constructed in the vector $\mathrm{pPNT}$ (22) using a 4-kb XhoI/SpeI fragment for the $5^{\prime}$ arm, and a $2.2-\mathrm{kb} \mathrm{SmaI} /$ NotI fragment for the $3^{\prime}$ arm. After homologous recombination, exons 4-7 of spp1 are thus replaced by phosphoglycerokinase (PGK) neomycin resistance gene (neor), with an hsv-tk cassette (for herpes simplex virusthymidine kinase) outside the region of homology. Transcription of PGKneo and hsv-tk occur in the opposite direction to the spp1 locus.

\section{Generation of recombinant ES cell lines and chimeric mice}

TL-1 ES cells $\left(20 \times 10^{6}\right.$ cells, at passage 10 [23]) were electroporated with $50 \mu \mathrm{g}$ linearized targeting vector with a single pulse at $800 \mathrm{~V}, 3 \mu \mathrm{F}$. Cells were fed daily with DME containing 1,000 U/ml leukemiainhibitory factor (ESgro; GIBCO BRL, Gaithersburg, MD). The next day, selection was started with $300 \mu \mathrm{g} / \mathrm{ml}$ active G418 (GIBCO $\mathrm{BRL}$ ), followed $2 \mathrm{~d}$ later with the addition of gancyclovir to a final 2 $\mu \mathrm{M}$ concentration. After $8 \mathrm{~d}$, double resistant clones were picked. Six correctly targeted ES cell clones were identified. Three of these clones were injected into C57BL/6 blastocysts to generate chimeric animals. Chimeric males from each line were bred to Black Swiss or 129/SvJ females (Taconic Farms, Inc., Germantown, NY) to obtain heterozygous pups. No differences were noted between animals from different ES cell clones. The analyses described were done with animals on a $129 \times$ Black Swiss hybrid background. The mutant allele has been designated $s p p 1^{t m l b l h}$ in accordance with standard nomenclature (24), and has been submitted to TBASE under the accession number TG-000-04-502 (http://www.bis.med.jhmi.edu/Dan/tbase/tbase.html).

\section{Genotyping of OPN mice}

Southern blotting. Genomic DNA was isolated and digested with XhoI, SphI, or SpeI. For initial screening, DNA was digested with XhoI, and blots were probed with probe C (see Fig. $2 A$ ). Genotypes were verified by probing SpeI-digested samples with probes A or B, which are outside the region of homology.

PCR analysis. The following primers were used: OPIn3, 5'CCATACAGGAAAGAGAGACC3'; OPIn4, 5'AACTGTTTTGCTTGCATGCG3'; Neo1360, 5'CGTCCTGTAAGTCTGCAGAA3'. OPIn3 and OPIn4 amplify an endogenous 600-bp fragment, and OPIn 3 and Neo1360 amplify a 500-bp fragment from the recombined mutant allele. The three primers were used together at an annealing temperature of $53^{\circ} \mathrm{C}$.
Reverse transcription (RT) PCR analysis for spp1 transcript

Total RNA from cells was reverse transcribed with avian reverse transcriptase using oligo dT primers. Primers for spp1 were Ex6 and Ex7, which amplify a 410-bp cDNA and a $1.1-\mathrm{kb}$ genomic product at an annealing temperature of $50^{\circ} \mathrm{C}$, while control primers were from murine hypoxanthine phosphoribosyltransferase (HPRT), which were used at an annealing temperature of $50^{\circ} \mathrm{C}$. Ex6, 5'AATCGTCCCTACAGTCGATG3'; Ex7, 5'TAGGGTCTAGGACTAGCTTG3'; HPRT1, 5'GCTGGTGAAAGGGACCTCT3'; and HPRT2, 5'CACAGGACTAGAACACCTGC3'.

\section{Immunohistochemistry}

Immunostaining for OPN was performed with purified goat IgG of an antibody generated against rat OPN, OP199 (25). Antibody was used at a concentration of 10-18 $\mu \mathrm{g} / \mathrm{ml}$. Detection was done using either a peroxidase-conjugated anti-goat IgG at 1:200 dilution (Jackson ImmunoResearch Laboratories, West Grove, PA) followed by incubation with the chromogen diaminobenzidine with nickel, or a biotinylated anti-goat IgG followed by detection using the ABC Elite method (Vector Laboratories, Inc., Burlingame, CA) with diaminobenzidine as the substrate. Macrophage immunostaining in incisional wounds was performed with the anti-murine pan-macrophage antibody BM8 (Accurate Chemical and Science Corp., Westbury, NY) at 1:100 dilution, followed by a biotinylated anti-rat IgG (Vector Laboratories, Inc.) at 1:100 dilution. Detection was performed using the ABC Elite kit (Vector Laboratories, Inc.) with diaminobenzidine as the substrate. For analysis of cell number, positive cells were counted as number/area of high power $(\times 60)$ field. Fields in the incision plane in the subepithelial regions were quantitated, and sections from five animals per group were analyzed.

\section{Skin incisional wounding}

Groups of 3-mo-old mice that were either wild-type or OPN null mutant $(129 \times$ Black Swiss $)$ were anesthetized with ketamine/xylazine and shaved. A single longitudinal full-thickness incision was made in the dorsal skin, and the margins were closed with wound clips. At the given time after wounding, skin samples were collected. For histology and immunohistochemistry, skin wounds were fixed in $4 \%$ paraformaldehyde and paraffin embedded. Wounds were either prepared fresh (or previously frozen) or after fixation in $10 \%$ buffered formalin for tensile strength analysis using a tensiometer (Instron Corp., Canton, MA). Tensile strength was calculated as force per volume of tissue. The numbers of animals used per group were as follows: 7-d wild-type and mutant mice, $n=4$ each, 14-d wild-type mice, $n=38$, and mutant mice, $n=52$. For normal skin, the number of animals used per group were wild-type mice, $n=23$, mutant mice, $n=31$. Statistical analysis was performed using the Student's $t$ test.

\section{In situ hybridization}

In situ hybridization was performed as described (26) using $\left[\alpha-{ }^{35} \mathrm{~S}\right]$ UTP riboprobes synthesized from the spp1 cDNA. Skin incisions were analyzed for expression using the sense probe as a negative control, where no signal was detected.

\section{Transmission electron microscopy}

Tissue processing. Dermal samples were fixed by immersion in $2 \%$ glutaraldehyde in phosphate buffer overnight at $4^{\circ} \mathrm{C}$, washed, and stored in $0.2 \mathrm{M}$ cacodylate buffer. Processing was as described (27). Briefly, tissues were dissected and postfixed with $1 \%$ osmium tetroxide. After dehydration in an ethanol series followed by propylene oxide, the tissues were infiltrated and embedded in a mixture of Polybed 812 , nadic methyl anhydride, dodecenylsuccinic anhydride, and DMP-30 (Polysciences, Inc., Warrington, PA). Sections were prepared using an ultramicrotome (Ultracut E; Reichert Ophthalmic Instruments, A Division of Leica, Buffalo, NY) and a diamond knife. Staining was with $2 \%$ aqueous uranyl acetate followed by $1 \%$ phosphotungstic acid, $\mathrm{pH}$ 3.2. Sections were examined and photographed at $80 \mathrm{kV}$ using a transmission electron microscope (model CM10; Philips, Eindhoven, The Netherlands). 


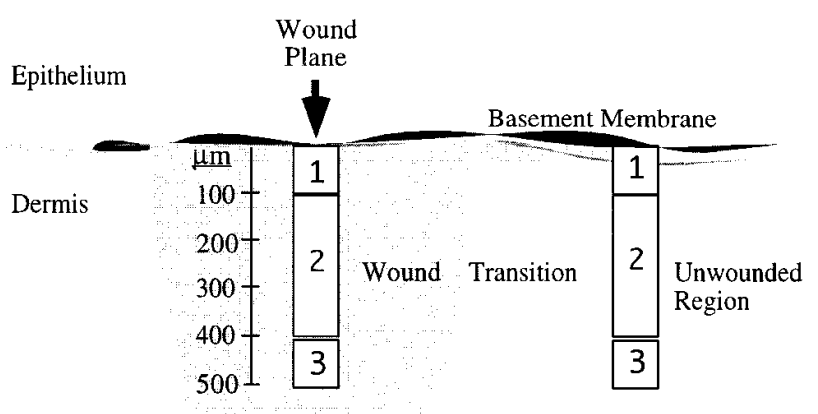

Figure 1. Analysis of incisional wounds by transmission electron microscopy. Depicted is a cross section of the skin indicating the region of the wound plane (arrow). Dermal areas examined were directly subepithelial (region $1,100 \mu \mathrm{m}$ into the dermis), middermal (region 2 , from 100 to $400 \mu \mathrm{m}$ into the dermis), and deep dermal (region 3, $400-500 \mu \mathrm{m}$ into the dermis). Corresponding regions outside of the wound area were also examined (Unwounded region).

Analyses of dermal wounds. Three mutant and three wild-type male mice were analyzed, and the results were consistent within both groups. The wounds were analyzed using a series of overlapping micrographs. First, a subepithelial series was taken from the unwounded region through the wound to the opposite unwounded region. Another series was taken perpendicular to the epidermis at midwound and again in the peripheral unwounded region. For purposes of analysis, the dermis was divided into three zones as diagrammed in Fig. 1. Zone 1 is directly subepithelial, zone 2 is middermal, and zone 3 is referred to as the deep dermal region.

Fibril diameter measurements. Micrographs were chosen randomly from each of the three zones in the wound and the unwounded tissue. The fibril diameters were measured blind from calibrated micrographs. A grid was placed over the micrographs, and all fibrils within a given area were measured. For presentation, measurements were normalized using the internal $67-\mathrm{nm}$ repeat of the fibrils. The normalization factor was constant in all groups studied.

\section{Results}

Targeted mutation of sppl generates viable homozygous mutant mice. The genomic structure of the murine sppl gene has been characterized (28), and consists of seven exons, with the translational start site in exon 2. A targeting construct was designed to delete exons 4-7 of the gene and replace them with a neo $^{\mathrm{r}}$ cassette ( $p$ GKneo; Fig. $2 A$ ). The recombination was predicted to create a null mutation of the gene, since the majority of the coding region is deleted. Six correctly recombined ES clones were identified, and three were used to generate lines of mice on the $129 / \mathrm{SvJ} \times$ Black Swiss hybrid and $129 / \mathrm{SvJ}$ inbred backgrounds. Heterozygous mice on both backgrounds were healthy, with a wild-type phenotype. Breeding pairs were established from $s p p 1^{t m 1}$ heterozygous mice generated from two of the ES cell clones. Genotyping (Fig. 2 B) of several litters at

A
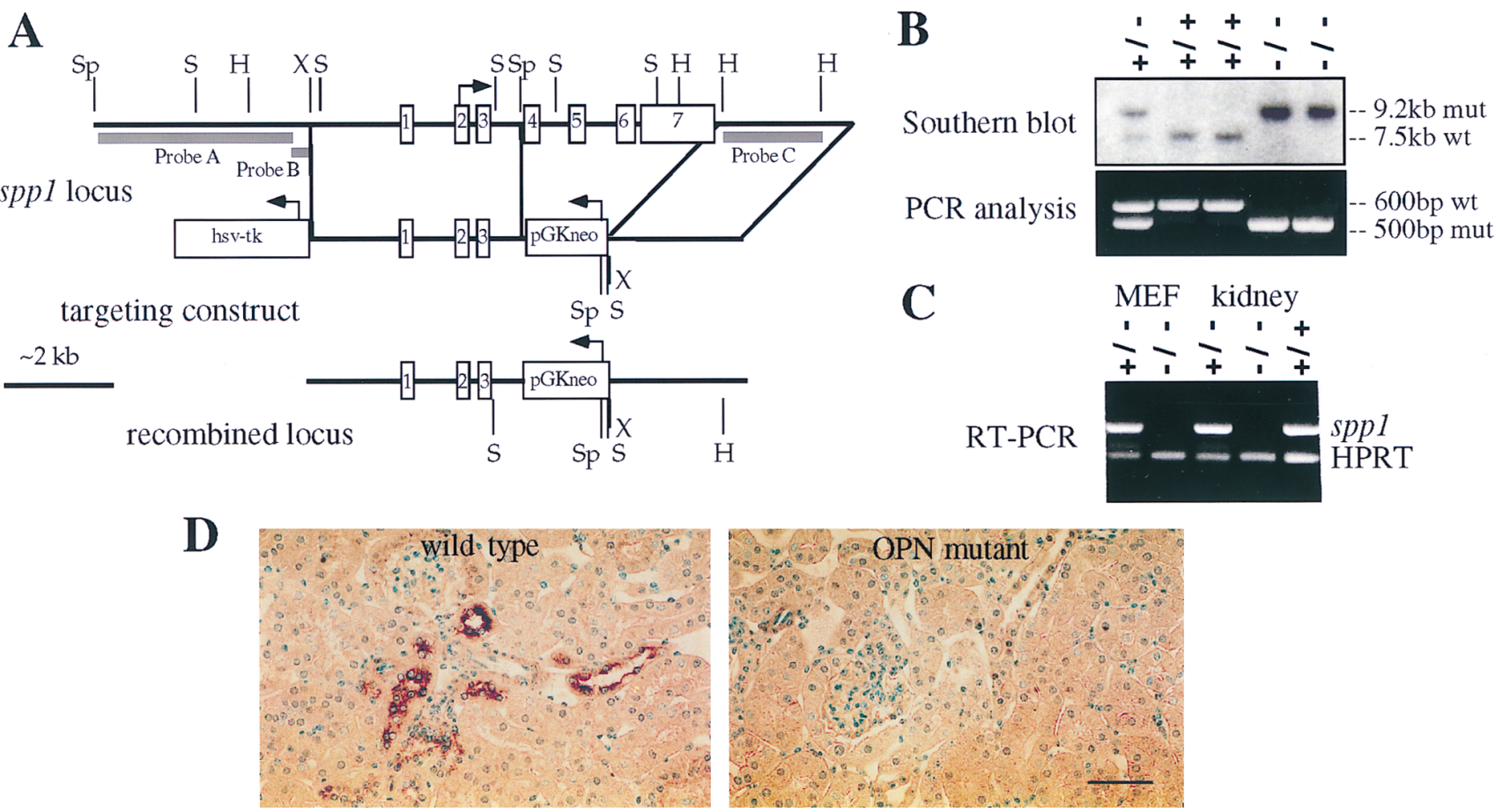

Figure 2. Targeted mutagenesis of the mouse spp1 locus. (A) The endogenous spp1 locus is depicted (top), with exons shown as numbered boxes. The homology regions of the $5^{\prime}$ and $3^{\prime}$ arms are indicated. Homologous recombination will yield the recombined locus shown. Probes A, $\mathrm{B}$, and $\mathrm{C}$ were used for Southern blot analysis and are indicated. $S p$, SpeI; $S, \mathrm{SphI} ; X$, XhoI; and $H$, HincII restriction enzymes. (B) Genotyping of the spp1 mutation using Southern blot and PCR analyses. DNA digested with SpeI and probed with either probe A or B yields a 7.5-kb wildtype fragment $(w t)$ and a 9.2-kb recombined fragment (mut). PCR analysis using the wild-type-specific primer in intron 4 and the mutant-specific primer in the neo ${ }^{\mathrm{r}}$ cassette. $(C)$ RT-PCR using total RNA from MEF or adult kidney from mice of indicated genotypes. Reactions amplified either spp1 or HPRT. (D) Immunohistochemistry on adult kidney sections from wild-type or OPN mutant mice using OP199 antibody. Bar, $40 \mu \mathrm{m}$. 
weaning demonstrated the expected Mendelian ratio of homozygous mutant offspring. The spp $1^{t m 1}$ homozygous mutant mice were phenotypically normal, and no abnormalities were noted in growth, external morphology, or behavior compared with wild-type littermates. In addition, both male and female mutants were completely fertile, giving birth to normal sized litters, and raising pups successfully to weaning.

spp1 mutagenesis results in an OPN null mutation. Several methods were used to verify that the targeted mutation of spp1 inactivated the gene. RT-PCR was performed using RNA collected from mouse embryonic fibroblasts (MEF) derived from heterozygous matings, and also from adult kidneys from wildtype or mutant animals. No sppl transcript was detected in homozygous samples, although a product was amplified in samples from heterozygous or wild-type animals (Fig. $2 C$ ). The absence of transcript in OPN mutant mice was confirmed by in situ hybridization using a riboprobe generated from the fulllength spp1 cDNA. In the OPN mutant, transcripts were not detected in regions where sppl is normally highly expressed (data not shown). Immunostaining was performed using an OPN antibody (25) in adult kidneys of wild-type or spp $1^{t m 1}$ homozygous mutant animals. In the normal adult kidney, OPN was produced in a subset of epithelial cells of the distal tubules (Fig. 2 D). In contrast, OPN protein was not detected in kidney tubules from OPN mutant animals (Fig. $2 \mathrm{D}$ ). Sections of bone from OPN mutant animals were also analyzed using antiOPN antibodies, and the results verified the absence of protein in the bone of mutant animals although bone structure was unaltered (M. McKee, data not shown). The complete absence of sppl mRNA and OPN protein in homozygous mutant animals demonstrates that our targeting scheme resulted in a null mutation.

Generation of mice lacking both OPN and VN. One explanation for the normal embryonic and reproductive phenotype of the OPN mutant animals is the presence of compensatory proteins. Of other RGD-containing proteins, VN shares binding specificity to at least three OPN receptors: $\alpha_{\mathrm{v}} \beta_{1}, \alpha_{\mathrm{v}} \beta_{3}$, and $\alpha_{v} \beta_{5}$ (29). A null mutation of the gene encoding VN (vtn) also results in viable and fertile mice (13). Therefore, it was of great interest to test the hypothesis that $\mathrm{VN}$ and OPN were functionally replacing each other in the respective mutant mice. Using the BSS interspecific backcross panel (The Jackson Laboratory, Bar Harbor, ME) (30), we confirmed (31) and extended the localization of the $v$ th gene to central chromosome 11, (data available at www.jax.org/resources/documents/cmdata). Since spp1 is located on chromosome 5 (32), the double mutation was accomplished by breeding. Animals that were double homozygous for the spp1 and vtn mutations were born at the predicted ratios, and no defects were observed in their fertility rates.

Expression of spp1 during incisional wound healing. Since sppl is transiently expressed at high levels in the inflammatory cells entering skin wounds (16), we tested the healing of incisional wounds by histological, ultrastructural, and physiological analyses in the OPN mutant mice. To establish the temporal expression of sppl during the healing process, in situ hybridization was performed on incisions from wild-type mice collected at $6,12,24$, and $48 \mathrm{~h}$, and at 3, 6, 9, and $12 \mathrm{~d}$ after injury. Whereas no expression was noted in nonwounded skin, sppl expression was upregulated as early as $6 \mathrm{~h}$ after injury, primarily in regions rich in infiltrating inflammatory cells at the wound margin (Fig. $3 A$ ). This expression persisted during the early inflammatory response and remained high at $12-72 \mathrm{~h}$ after wounding (Fig. 3, $B-E$ ), but decreased by 6 d (Fig. $3 F$ ). Expressing cells were localized to the dermal stroma, and at no time did keratinocytes of the epidermis express spp1. At higher magnification (Fig. 3, $G$ and $H$ ), we observed that positive cells included polymorphonuclear leukocytes, and immu-

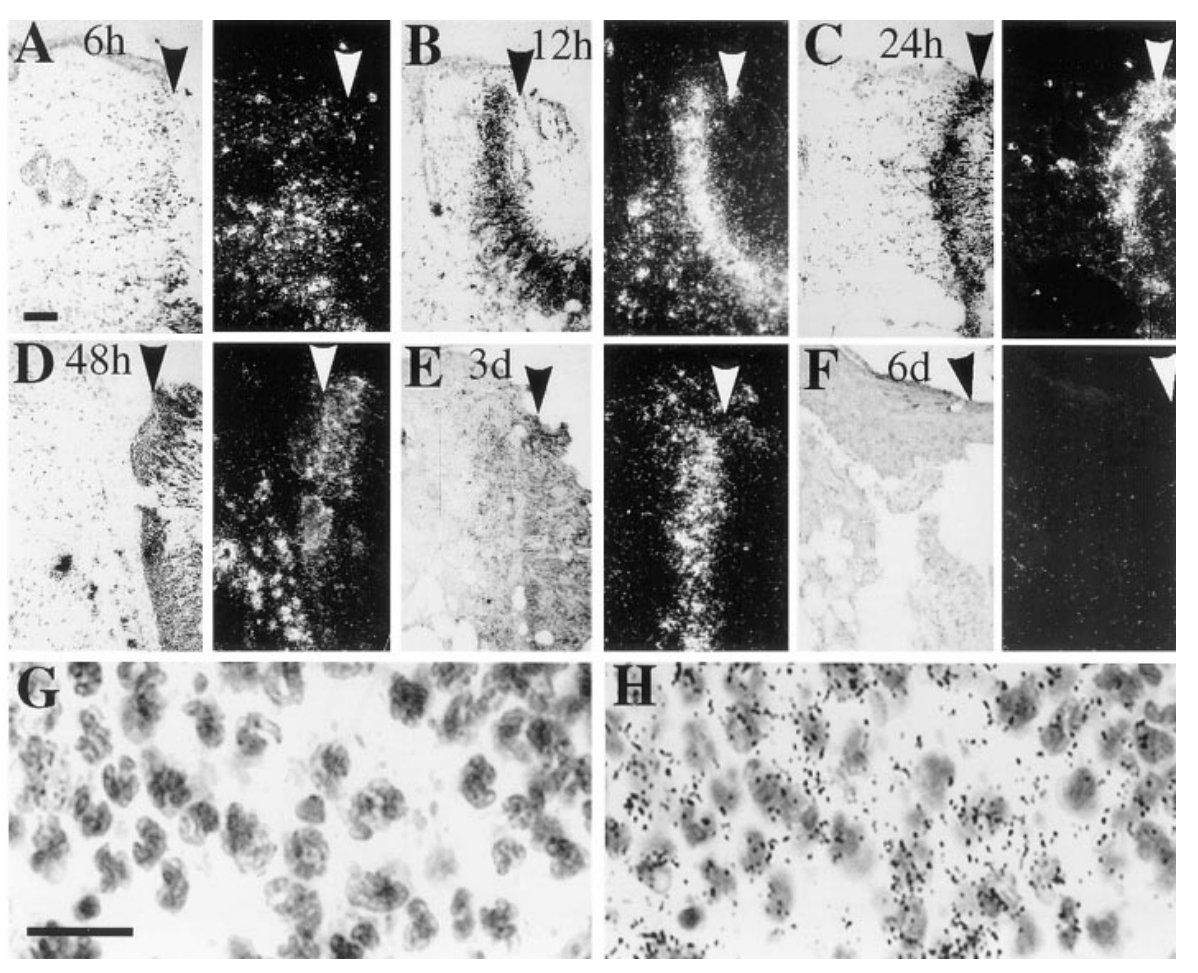

Figure 3. Expression of spp1 after skin incisional injury. Full-thickness skin incisions were collected at various times after injury, and in situ hybridization was carried out using an antisense $\left[{ }^{35} \mathrm{~S}\right]$ UTP-labeled spp1 riboprobe. Corresponding bright and dark field micrographs show strong spp1 expression in areas of infiltrating inflammatory cells as early as $6 \mathrm{~h}(A)$, localizing predominantly to the wound margin (arrowheads). Expression persisted at $12 \mathrm{~h}$ $(B), 24 \mathrm{~h}(C), 48 \mathrm{~h}(D)$, and $3 \mathrm{~d}(E)$ in the dermal stroma, particularly at the wound margin. By $6 \mathrm{~d}$ after injury, expression had decreased to uninjured levels $(F)$. ( $G$ and $H$ ) Higher power magnification of a single field of cells at the wound margin at $48 \mathrm{~h}$, with the plane of focus on the cell nuclei $(G)$ or silver grains $(H)$ to demonstrate nuclear morphology of spp1-expressing cells. Regions of expression are high in inflammatory cells. Scale bar in A, $50 \mu \mathrm{m}$ for $A-F$; bar in $\mathrm{G}, 80 \mu \mathrm{m}$ for $G$ and $H$. 

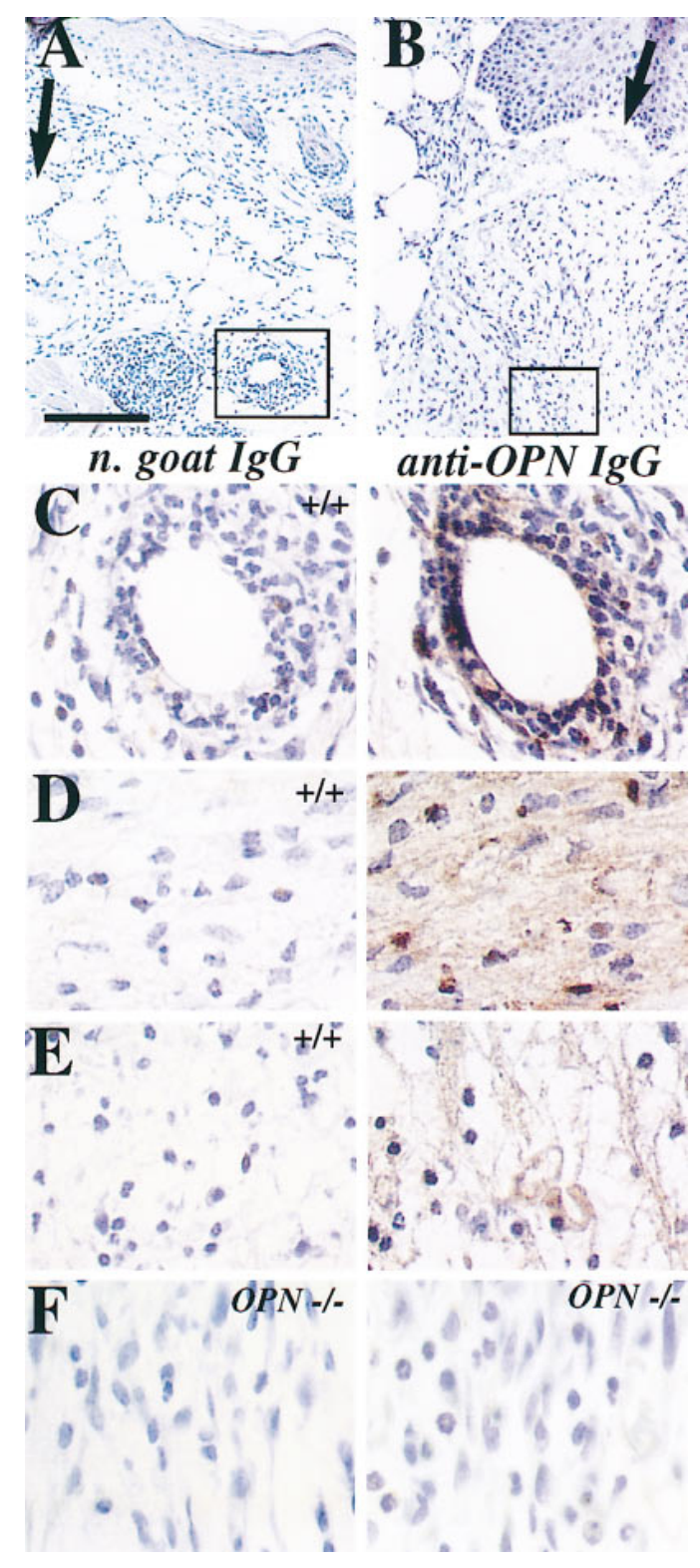

Figure 4. Localization of OPN in skin wounds. ( $A$ and $B$ ) Low magnification views of skin incisions $4 \mathrm{~d}$ after injury in wild-type animals, showing position of $C$ and $D$ (boxed regions) relative to the incision plane (black arrows). $(C-E)$ Serial sections of skin incisions $4 \mathrm{~d}$ after injury in wild-type animals stained with anti-OPN $\operatorname{IgG}($ right $)$ or normal goat IgG (left). (C) Higher magnification of region boxed in $A$, showing that positive cells were localized to regions surrounding vessels, possibly reflecting inflammatory cells entering the wound site. $(D)$ Higher magnification of boxed region in $B$, showing that OPN protein was both cell- and matrix-associated $(E)$. $(F)$ Two comparable sections from 4-d wounds of OPN null mutant animals were stained with anti-OPN IgG. No OPN was detectable in mutant animals. Sections were counterstained with hematoxylin. Scale bar, 400 $\mu \mathrm{m}$ for $A$ and $B$ and $100 \mu \mathrm{m}$ for $C-F$.

nostaining with an antimacrophage antibody in parallel sections identified sppl-expressing cells as macrophages as well. Although most positive cells appeared to correspond to inflammatory cells at the wound margin and adjacent to the eschar, it was not possible to exclude the possibility that dermal fibroblasts also expressed spp1. In situ hybridization of wounds from OPN mutant animals did not give signal above background (data not shown).

We further examined the protein localization of OPN using immunostaining of wounds from wild-type animals. As expected, protein was detected in the dermal stroma in 4-d wounds (Fig. 4). Protein was localized to regions directly in the incision wound plane (Fig. $4 \mathrm{~B}$, arrow indicates region of incision), as well as in adjacent regions (Fig. $4 A$ ). In addition to cell-associated staining (Fig. $4 C$ ), abundant extracellular staining was also seen (Fig. 4, $D$ and $E$ ), reflecting deposition of OPN in the matrix of the wound. Comparable sections of wounds from OPN null mutant animals were also immunostained, and no OPN was detectable in any mutant animals (Fig. $4 F$ ).

Morphological analysis of wounds from wild-type and $O P N$ mutant mice. Healing wounds were compared between wildtype and OPN null mutant mice during the repair process. The extent of reepithelization and general wound organization was similar between mutant and wild-type skin when analyzed using light microscopy (data not shown). However, ultrastructural analysis demonstrated several distinct differences between the mutant and wild-type wounds at 2 wk after injury. First, the wound regions in the OPN mutant mice contained more cell debris than corresponding regions in wild-type mice. The increased cell debris seen in mutant mice was most striking in the subepithelial dermis (zone 1; Fig. 5, $A$ and $B$ ). However, this difference was obvious throughout both the superficial and middermal zones (Fig. 5, $C$ and $D$ ). Since OPN has been shown to be a chemoattractant for macrophages, which are primarily responsible for debridement at the wound site, incisions were immunostained with a pan-macrophage antibody to test for differences in macrophage influx in wounds of normal or OPN mutant mice. Incisions at $4 \mathrm{~d}$ were chosen, since at this time macrophages have begun to appear in large numbers at the wound site. In both groups, there were high levels of macrophages throughout the incision, and the numbers were not significantly different between groups (means \pm SEM of wild-type mice $=43.8 \pm 7.8$, of OPN mutant mice $=$ 41.5 \pm 4.6$)$. However, the apparent lower level of debridement in the OPN mutants suggests that the activity of these macrophages may be compromised.

The second major difference between resolving wounds in wild-type and OPN mutant animals was that in the OPN mutant, the reforming matrix was less organized than in corresponding regions of wild-type mice. Specifically, in the subepithelial and middermal zones, the organization of collagen fibrils and fibers was not as distinct in the mutant compared with wild-type mice (Fig. 5, $A$ and $C$, wild-type, vs. Fig. 5, $B$ and $D$, mutant). Fibers were less organized and more difficult to define in the mutant mice. Finally, in the deep reticular dermis, the collagen fibrils in the OPN mutant mice were significantly smaller than fibrils in the corresponding region of the wild-type mice (Fig. 5, $E$ and $F$ ). This difference in fibril diameter in the wound is shown at higher magnification in Fig. 6 (left columns).

The differences in fibril diameters seen in the deep reticular dermis (zone 3) of the wound area in the OPN mutants compared with wild-type mice were significant. In the mutants, fibrils remained small, with a homogenous distribution at all wound levels (Fig. 6, second column, and Table I). In contrast, in the wild-type mice, fibrils became significantly larger, and 

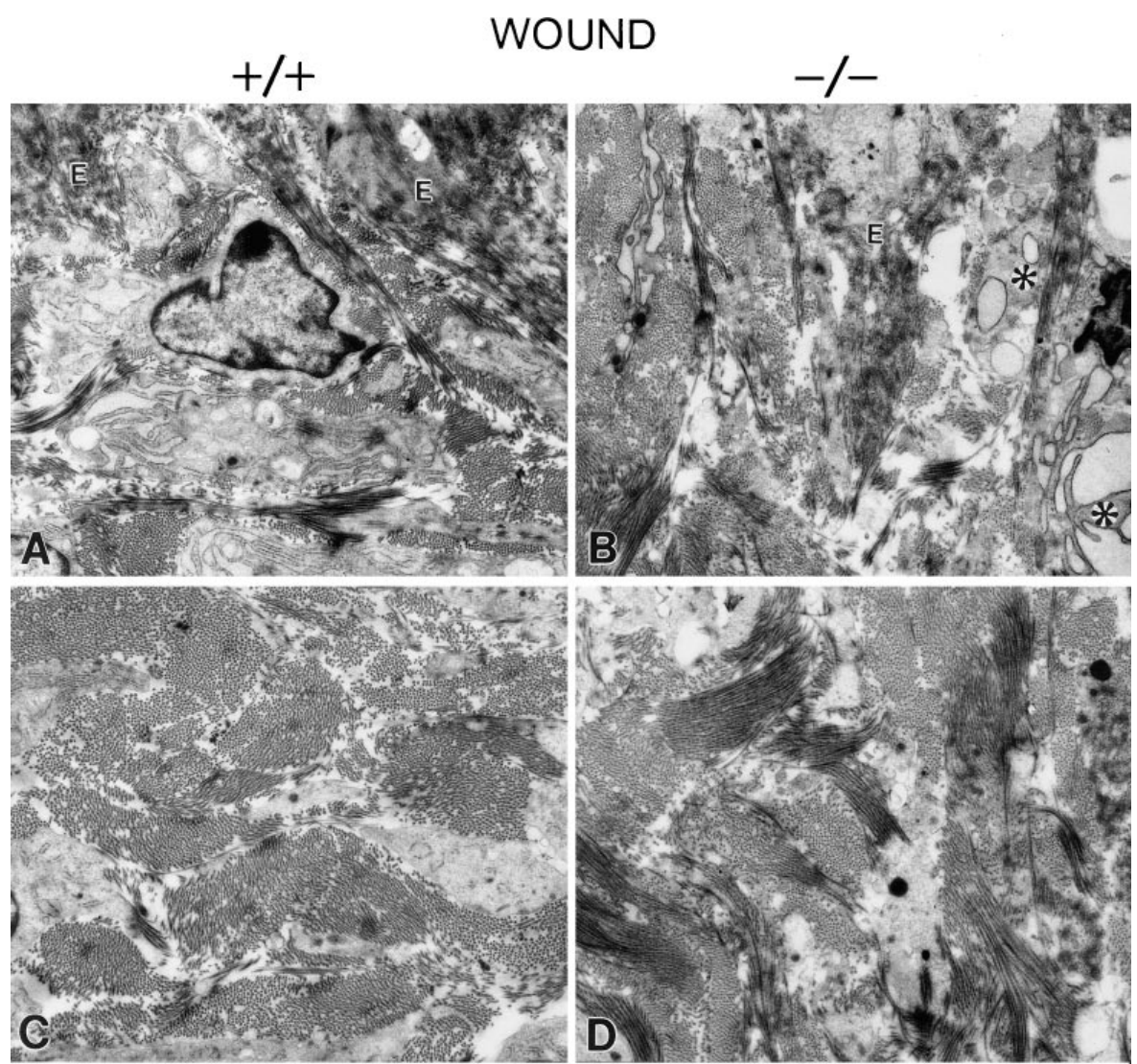

Figure 5. Differences in the reestablishment of matrix architecture after a fullthickness dermal wound in OPN mutant versus wild-type mice. Representative transmission electron micrographs from incisions $2 \mathrm{wk}$ after wounding in wild-type $(+/+$, left $)$ and OPN mutant $(-/-$, right $)$ mice. Three regions of the dermis were sampled: $(A$ and $B)$ zone 1 is subepithelial ( $E$, epithelium); $(C$ and $D)$ zone 2 is middermal; and $(E$ and $F)$ zone 3 is the deep dermal region (see Methods). The mutant mouse had more cell debris $(*)$ associated with the wound area than did the wild-type mouse ( $A$ vs. $B$ ). This was especially true in the subepithelial region (zone 1$)$. The reforming matrix was less organized in both zones 1 and 2 in the mutant compared with the normal control mouse ( $A$ and $C$ vs. $B$ and $D)$. The fibril diameters were significantly smaller in the deep dermal region of the mutant compared with the normal mouse ( $E$ vs. $F$ ) (see also Table I). However, comparable small diameter fibrils were seen in the wild-type mouse ( $E$, $a r$ rows). Sections were cut perpendicular to the epidermis, 100-125 nm thick, and stained with uranyl acetate/phosphotungstic acid. Bar, $1 \mu \mathrm{m}$.

there was a heterogeneous distribution of fibril diameters. The difference was readily apparent in the deep dermal region (Fig. 6, zone 3). Small diameter fibrils comparable to those seen in the deep dermis of the mutant mice were also present in the wild-type mice (Fig. 5 E, arrows). Although the reorganization of the matrix was significantly different in the wounds of OPN mutant mice compared with the wild-type controls, the normal unwounded skin in both groups was generally similar in terms of both tissue architecture and cell organization in the subepithelial (Fig. 7, $A$ and $B$ ), middermal (Fig. 7, $C$ and $D$ ), and deep dermal regions (Fig. 7, $E$ and $F$ ). Collagen fibril diameters were also comparable in the unwounded dermis of both wild-type and OPN mutants (Fig. 6, right columns, and Table I). In contrast to the wound regions in the OPN mutants, there was an increase in mean fibril diameter as well as development of a heterogeneous distribution of fibril diameters in unwounded dermis from the superficial to deep regions. There was no difference between the wild-type and mutant mice in this respect. Therefore, the differences in dermal organization between the OPN mutant and wild-type mice only appear to be significant in the context of the healing process.

Tensile strength of healing incisional wounds. We tested whether the differences in collagen organization in the OPN mutant mice led to changes in tensile strength, a measure thought to be determined predominantly by fibrillar collagen deposition and remodeling. Samples were collected at 7 and $14 \mathrm{~d}$ after injury and tested either fresh or after fixation. Fig. $8 \mathrm{~A}$ shows that no significant differences in tensile strength were apparent at 7 or $14 \mathrm{~d}$ between normal and mutant mice. One consistent finding was that regardless of genotype, there was a significantly greater fresh tensile strength of male versus female skin 2 wk after injury (Fig. $8 \mathrm{~B}$ ). In normal unwounded skin, the same results were noted. There was no significant difference in normal skin strength as a function of genotype, 

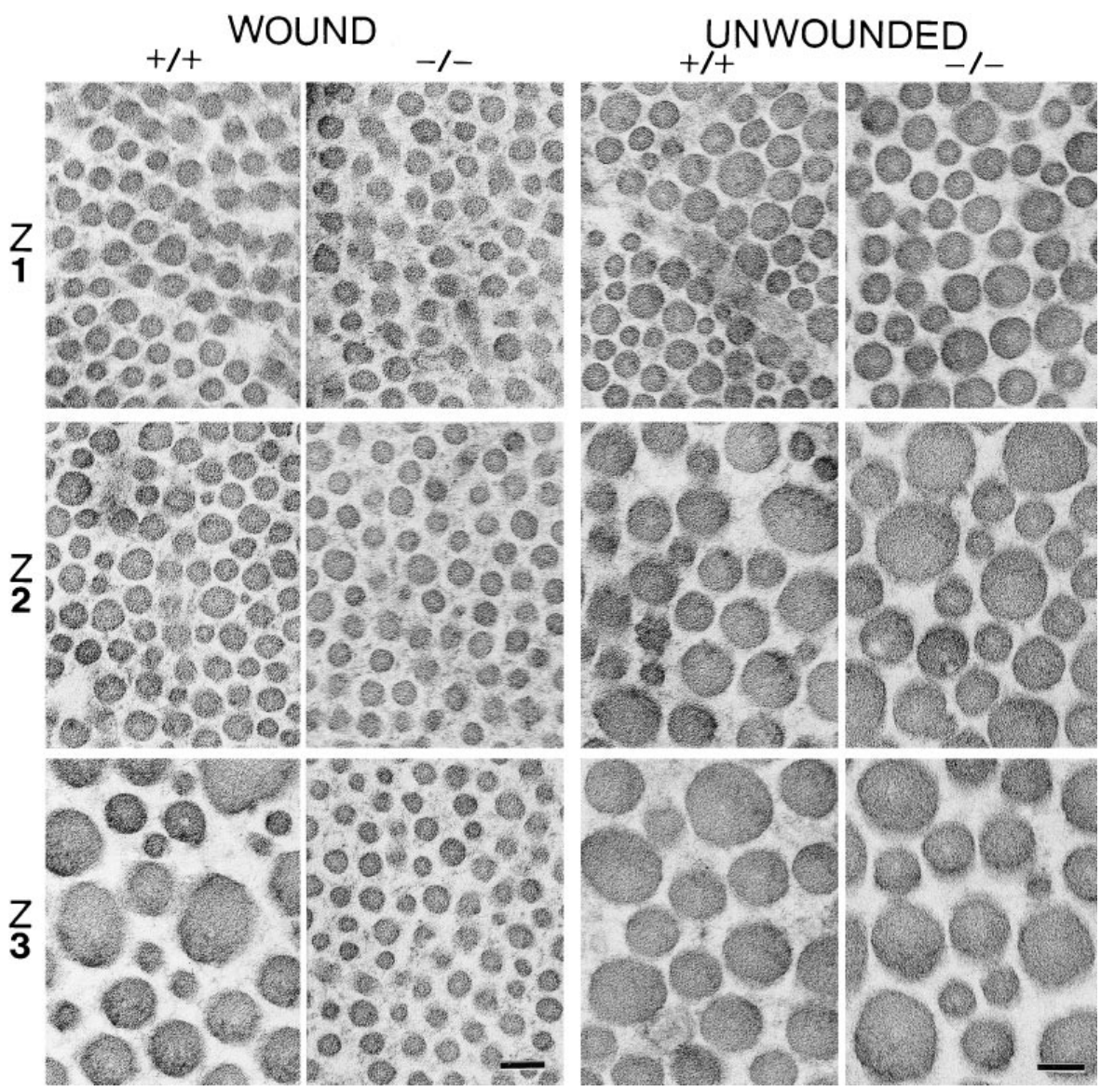

Figure 6. Alterations in collagen fibril formation after a full-thickness dermal wound in OPN mutant mice. Collagen fibril diameters remained small, with a homogenous distribution at all wound levels in the OPN mutant mouse (WOUND -/-), while in the wild-type mouse, fibril diameters became significantly larger, with a heterogenous distribution of diameters (WOUND $+/+$ ) (compare zone [Z] 3, WOUND +/+ vs. $-/-$ ). In contrast, fibril formation was comparable in unwounded dermis in wildtype (UNWOUNDED +/+) versus OPN mutant (UNWOUNDED -/-) mice. Sections are $100-125 \mathrm{~nm}$ thick and stained with uranyl acetate/phosphotungstic acid. Bar, $100 \mathrm{~nm}$.

but there was a very large difference as a function of gender (Fig. $8 \mathrm{C}$ ).

\section{Discussion}

Functional compensation between $O P N$ and $V N$-related proteins during embryogenesis. Targeted mutation of genes has been accomplished for several adhesive proteins and their receptors, including RGD-containing proteins and members of the integrin family (33). In many cases, the phenotypes of the mutants are unexpected, with animals presenting with no obvious defects, or surviving to later stages of development than the expression pattern or in vitro evidence would predict. One interpretation of these findings is that proteins with shared functional domains or receptors compensate for each other's absence during embryogenesis. Our findings reported here of a normal phenotype in spp1 mutant mice suggest that there are complex functional interactions among RGD-containing integrin ligands during embryogenesis. In addition, the in vivo roles of OPN may also be mediated through nonintegrin receptors. One possible explanation for the normal embryonic phenotype even in the sppl/vtn double mutant mice is a functional compensation by other extracellular proteins. The $\alpha_{v} \beta_{3}$ integrin is a predominant receptor for both OPN and VN, and can also bind thrombospondin, tenascin, fibronectin, and others. Interestingly, single mutations in the genes encoding

Table I. Collagen Fibril Diameters in Wild-type versus OPN Mutant Skin

\begin{tabular}{|c|c|c|c|c|c|c|}
\hline & $\begin{array}{c}+/+ \\
\text { Zone } 1\end{array}$ & $\begin{array}{c}+/+ \\
\text { Zone } 2\end{array}$ & $\begin{array}{c}+/+ \\
\text { Zone } 3\end{array}$ & $\begin{array}{c}-/- \\
\text { Zone } 1\end{array}$ & $\begin{array}{c}-/- \\
\text { Zone } 2\end{array}$ & $\begin{array}{c}-/- \\
\text { Zone } 3\end{array}$ \\
\hline \multicolumn{7}{|l|}{ Wounded } \\
\hline Mean \pm SD $(\mathrm{nm})$ & $65 \pm 11$ & $63 \pm 12$ & $107 \pm 51$ & $56 \pm 8$ & $58 \pm 7$ & $54 \pm 9$ \\
\hline Range (nm) & $16-91(n=359)$ & $22-93(n=354)$ & $26-310(n=399)$ & $23-82(n=270)$ & $29-82(n=345)$ & $21-73(n=264)$ \\
\hline \multicolumn{7}{|l|}{ Unwounded } \\
\hline Mean \pm SD $(\mathrm{nm})$ & $87 \pm 27$ & $101 \pm 33$ & $126 \pm 39$ & $80 \pm 18$ & $110 \pm 37$ & $116 \pm 29$ \\
\hline Range (nm) & $37-308(n=287)$ & $30-280(n=297)$ & $42-283(n=275)$ & $37-149(n=187)$ & $28-322(n=298)$ & $45-252(n=314)$ \\
\hline
\end{tabular}

Random fields were selected in three zones from superficial to deep dermis for quantitation of fibril diameters (see Methods). Shown are means, SD, range, and the number of fibrils measured from 2 -wk incisional wounds and unwounded skin. Data from three wild-type animals $(+/+)$ and three OPN mutant animals $(-/-)$ are represented. 


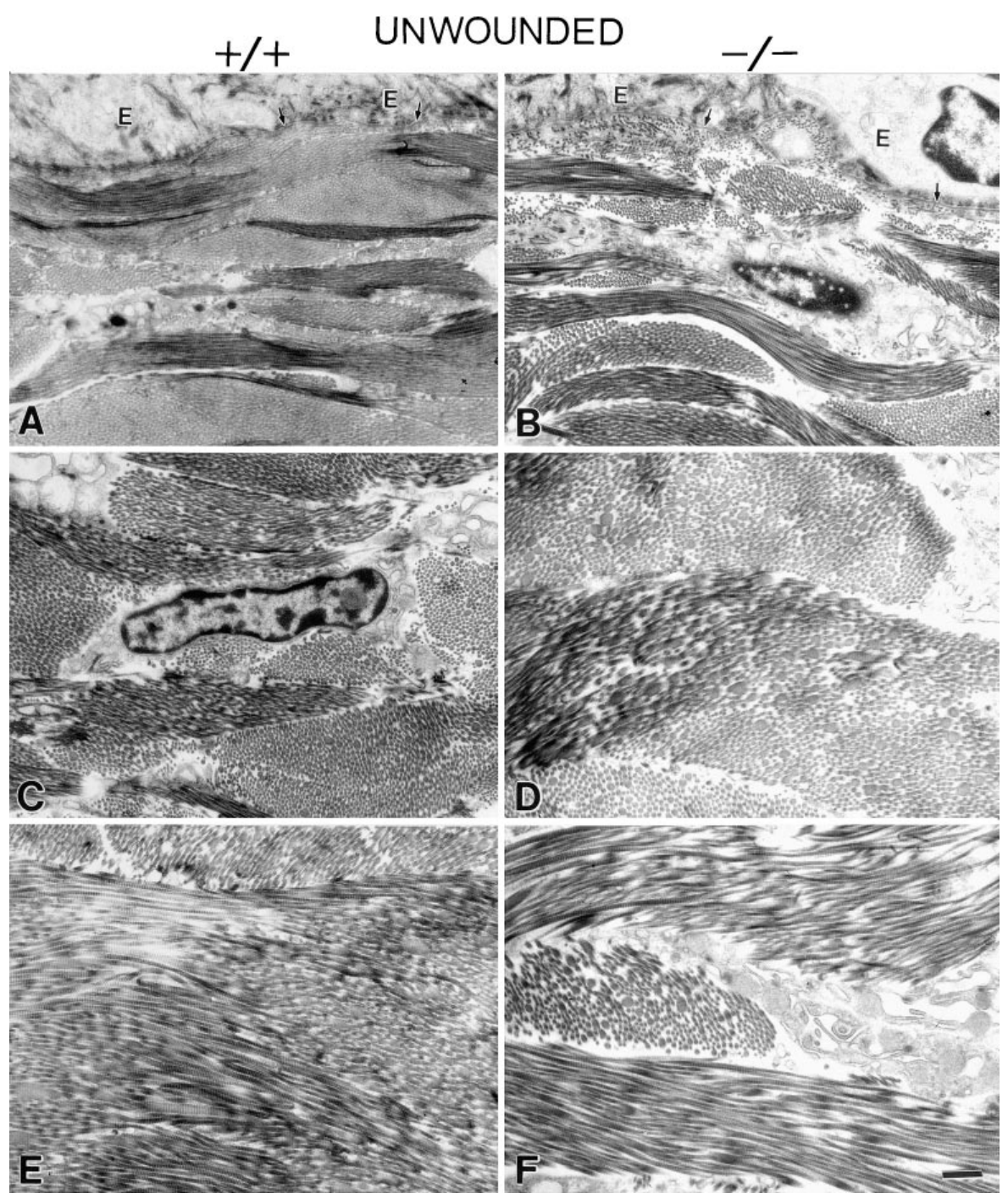

Figure 7. Comparison of dermal architecture from unwounded regions in OPN mutant and wild-type mice. The architecture and cell organization at all levels in the unwounded regions peripheral to the wounds were comparable in OPN mutant and wildtype mice. The fibrillar matrix was better organized in unwounded regions compared with the adjacent wounded regions (compare with Fig. 5). In contrast to the wound, fibril diameters increased from the superficial to deep dermis in both unwounded wild-type and OPN mutant mice (compare with Fig. 6, and see Table I). Transmission electron micrographs with the sections cut perpendicular to the epidermis, 100-125 nm thick, and stained with uranyl acetate/ phosphotungstic acid. ( $A$ and $B$ ) Zone 1 ; $(C$ and $D)$ zone 2; $(E$ and $F)$ zone 3. E, Epithelium. Arrows in $A$ and $B$, Basement membrane. Bar, $1 \mu \mathrm{m}$. thrombospondin-1, tenascin-C, OPN, and VN do not lead to developmental defects. However, inactivation of the $\alpha_{v}$ integrin, a component of their shared receptors, causes embryonic and perinatal lethality (33). These data are consistent with the idea that loss of one or two of these proteins can be compensated for by another ligand that signals through a common receptor.

Role of OPN during wound healing-inflammatory phase. We have studied wound healing in skin incisions, where the initial component of repair is hemostasis and an inflammatory response. During the inflammation phase, sppl was expressed at high levels in regions of infiltrating leukocytes. This expression was seen as early as $6 \mathrm{~h}$ after wounding with the first influx of neutrophils, and was also seen in macrophages as they entered the wound site. Since all cell types expressing spp1 could not be identified definitively in the stroma, it is likely that fibroblasts may also be a source of OPN. Previous in vivo data have demonstrated that injection of OPN led to an accumulation of macrophages and, to a lesser extent, polymorphonuclear leukocytes (15). In addition, OPN affects B cell and macrophage function (34), and thus is postulated to act as a cytokine for $\mathrm{T}$ cells, as well as a chemoattractant for macrophages (6). This latter hypothesis has been validated in a model of renal tubulointerstitial disease in vivo, where macrophage influx into the injury site is decreased significantly in the OPN null mutant mouse (Ophascharoensuk, V., C.M. Giachelli, L. Liaw, K. Gordon, R. Schmidt, C.E. Alpers, S.J. Shankland, W.G. Couser, and R.J. Johnson, manuscript submitted for publication). In the case of the cutaneous wound model, although the numbers of macrophages were similar in wild-type and mutant animals, our findings support a role for OPN in the activation or function of these macrophages. Incisions in OPN mutants showed a marked decrease in the level of debridement, suggesting that the phagocytes are less active in the removal and degradation of damaged connective tissue. We have also examined the expression of macrophage markers modulated upon cell activation, including the mannose receptor (35). Our preliminary findings indicate that macrophages in wounds of OPN mutant animals have a higher level of mannose receptor compared with wild-type animals. Since a decrease in mannose receptor in macrophages correlates with their activation (36), this suggests that a greater proportion of macrophages in the OPN mutant wounds are not activated. Taken together, these findings support a model where the processes of macrophage 

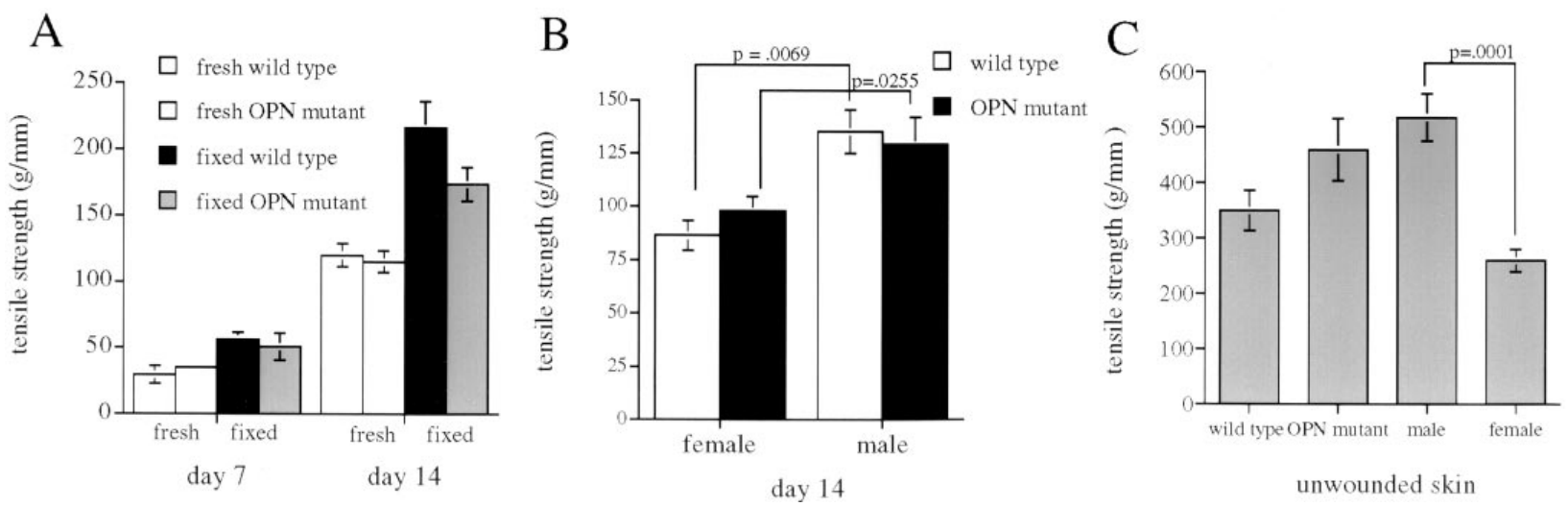

Figure 8. Tensile strength analysis of incisions from wild-type or OPN mutant mice. $(A)$ Skin incisions were collected at 7 and $14 \mathrm{~d}$ after injury, and either prepared fresh or after fixation (fixed). There was no significant difference between the wild-type or OPN mutant groups under any condition tested. $(B)$ Tensile strength of fresh skin incisions was evaluated as a function of gender. There was a significantly greater incision strength in male versus female animals. $(C)$ Tensile strength of normal skin in wild-type or OPN mutant animals. Uninjured fresh skin was analyzed by both genotype and gender. There was no significant difference between tensile strengths of wild-type and OPN mutant animals, but there was a significantly greater strength of normal skin from male compared with female animals. Means \pm SEM are graphed.

chemotaxis, activation, or phagocytic activity are mediated in part by OPN at the wound site. A similar idea has been proposed during wound healing in bone, where OPN secreted by macrophages is postulated to be required for cell adhesion and phagocytosis (37). Thus, one explanation for the high levels of OPN at wound sites is that the protein stimulates immune activity. Data from several labs posit that this model may be applicable to dermal wound repair, cardiovascular remodeling, and wound healing of bone.

$O P N$ and collagen fibrillogenesis. After the inflammatory phase, granulation tissue forms, and there is maturation and remodeling of the matrix. There was a significant difference in matrix organization and collagen fibrillogenesis in the OPN mutants compared with controls. In the incisions of wild-type animals at $2 \mathrm{wk}$, collagen fibrils were organized into welldefined fibers composed of a heterogeneous mixture of fibrils of varying diameter, including coarse fibrils in the deep dermis. However, the incisions in OPN mutant mice had a more disorganized matrix overall, with less collagen organization into fibers. The fibers that were present were composed only of homogeneous smaller diameter fibrils. One possibility for these differences is that OPN may affect the synthesis and/or turnover of matrix components involved in the regulation of fibril formation, either by affecting the types of collagens synthesized, or by association with proteins present in the remodeling wound. Regulation of fibril formation at this step involves heterotypic interactions of fibrillar collagens and the extent of amino-terminal processing. Collagen type III is a marker of the immature wound (38), and heterotypic interaction of different collagens is thought to regulate fibril size. In support of this idea, mice with a targeted mutation of the gene encoding type III procollagen (Col3a1) formed dermal collagen fibers of greater diameter than wild-type animals (39), and a point mutation in Col3a1 likewise led to matrix disorganization and collagen fibril diameter heterogeneity $(40,41)$. The loss of collagen type III during tendon development also correlates with increases in collagen fibril diameter (42), and analysis of human skin has shown that large collagen fibrils consist mostly of type I, while smaller fibrils contain type III collagen. There- fore, one possible cause of the persistence of smaller fibrils in the OPN mutant wounds is the disregulation of matrix synthesis.

Presumably as the wound resolves itself, the collagen fibrils mature. It has been suggested that this involves the destabilization of the immature fibrils followed by fusion, yielding longer and larger diameter fibrils $(43,44)$. Collagen-binding molecules that have been demonstrated to regulate this step include the small leucine-rich proteoglycans decorin, fibromodulin, and lumican. These proteoglycans have been implicated in the regulation of several parts of collagen fibrillogenesis (45), a role supported by the phenotype of the decorin null mutant mice, where uncontrolled lateral fusion of collagen fibrils occurs (46). The absence of OPN in the wounds of the mutant mice could alter synthesis of molecules that are involved in the stabilization or turnover of these components, such as the leucine-rich proteoglycans or matrix metalloproteinases, which are also known to be produced during skin injury (reference 47, and Crawford, H.C., J.H. Wright, J. Mudgett, and L.M. Matrisian, manuscript submitted for publication). A maintenance of stable immature fibrils would explain the wound phenotype observed in the OPN mutant mice.

OPN may also interact directly with collagen or the other proteins discussed above. OPN has been shown to bind directly to collagen type I (48), and to interact with collagen types II, III, IV, and V (49), and fibronectin (50), although it is not certain when such interactions occur in connective tissues in vivo. In mineralized tissues such as the tooth, OPN has been localized by immunocytochemistry to specific regions of collagen fibrils (51). Whether by a direct or indirect mechanism, lack of OPN in the wound appears to alter matrix assembly, leading to disorganization in the resolution of the wound. Since matrix organization was normal in the unwounded skin of OPN mutants, these functions may be replaced by other proteins during development. Alternatively, different processes may be involved during embryogenesis versus adult wound healing. Long-term observation of residual scar tissue is needed to determine whether continued remodeling in the OPN mutants eventually normalizes matrix architecture. 
In summary, we report the first establishment of OPN null mutant mice, which are viable, thus providing the opportunity to determine the in vivo functions of OPN during disease or tissue remodeling. Further experiments are necessary to understand fully the functions of OPN during incisional wound healing, but we provide evidence for a role in stimulation of macrophage function, and regulation of collagen fibrillogenesis. These findings indicate an in vivo role of OPN in the structural remodeling and resolution of dermal wounds.

\section{Acknowledgments}

We are grateful to Xianxian Zheng and David Ginsburg (University of Michigan, Ann Arbor, MI) for providing the VN mutant mice. We also thank members of the laboratories of Richard Johnson and Charlie Alpers (University of Washington, Seattle) for their contributions to immunostaining and ultrastructural analysis of kidney, respectively; Marc McKee (University of Montreal, Montreal, Canada) for ultrastructural analysis of bone; Virginia Shepherd (Vanderbilt University, Nashville, TN) for macrophage expertise; and Julie Blackwell-Fowler for excellent technical assistance.

L. Liaw is the recipient of a Developing Scientist Award from the American Heart Association. This work was supported in part by National Institutes of Health grant AG-06528 and the Department of Veterans Affairs (J.M. Davidson). B.L.M. Hogan is an Investigator of the Howard Hughes Medical Institute.

\section{References}

1. Franzén, A., and D. Heinegård. 1985. Isolation and characterization of two sialoproteins present only in bone calcified matrix. Biochem. J. 232:715724.

2. Oldberg, A., A. Franzén, and D. Heinegård. 1986. Cloning and sequence analysis of rat bone sialoprotein (osteopontin) cDNA reveals an arg-gly-asp cell-binding sequence. Proc. Natl. Acad. Sci. USA. 83:8819-8823.

3. Senger, D.R., D.F. Wirth, and R.O. Hynes. 1980. Transformation-specific secreted phosphoproteins. Nature. 286:619-621.

4. Smith, J.H., and D.T. Denhardt. 1987. Molecular cloning of a tumor promoter-inducible mRNA found in JB6 mouse epidermal cells: induction is stable at high, but not at low, cell densities. J. Cell. Biochem. 34:13-22.

5. Patarca, R., G.J. Freeman, R.P. Singh, F.-Y. Wei, T. Durfee, F. Blattner, D.C. Regnier, C.A. Kozak, B.A. Mock, J.C. Morse III, et al. 1989. Structural and functional studies of the early T-lymphocyte activation 1 (Eta-1) gene. Definition of a novel $\mathrm{T}$ cell-dependent response associated with genetic resistance to bacterial infection. J. Exp. Med. 170:145-161.

6. Weber, G.F., and H. Cantor. 1996. The immunology of Eta-1/osteopontin. Cytokine Growth Factor Rev. 7:241-248.

7. Denhardt, D.T., C.A. Lopez, E.E. Rollo, S.M. Hwang, X.R. An, and S.E. Walther. 1995. Osteopontin-induced modifications of cellular functions. Ann. NY Acad. Sci. 760:127-142.

8. Thayer, J.M., C.M. Giachelli, P.E. Mirkes, and S.M. Schwartz. 1995. Expression of osteopontin in the head process late in gastrulation in the rat. $J$. Exp. Zool. 272:240-244.

9. Fan, C.M., and M. Tessier-Lavigne. 1994. Patterning of mammalian somites by surface ectoderm and notochord: evidence for sclerotome induction by a hedgehog homolog. Cell. 79:1175-1186.

10. Nomura, S., A.J. Wills, D.R. Edwards, J.K. Heath, and B.L.M. Hogan. 1988. Developmental expression of 2ar (osteopontin) and SPARC (osteonectin) RNA as revealed by in situ hybridization. J. Cell Biol. 106:441-450.

11. Seiffert, D., T.J. Podor, and D.J. Loskutoff. 1993. Distribution of vitronectin. In Biology of Vitronectins and Their Receptors. K.T. Preissner, S. Rosenblatt, C. Kost, J. Wegerhoff, and D.F. Mosher, editors. Elsevier Science B.V., Amsterdam. 75-81.

12. Cooper, S., W. Bennett, S. Roach, and M.F. Pera. 1993. Vitronectin expression in human germ cell tumours and normal mouse development. In Biology of Vitronectins and Their Receptors. K.T. Preissner, S. Rosenblatt, C. Kost, J. Wegerhoff, and D.F. Mosher, editors. Elsevier Science B.V., Amsterdam. 8390.

13. Zheng, X., T.L. Saunders, S.A. Camper, L.C. Samuelson, and D. Ginsburg. 1995. Vitronectin is not essential for normal mammalian development and fertility. Proc. Natl. Acad. Sci. USA. 92:12426-12430.

14. Brown, L.F., A. Papadopoulos-Sergiou, B. Berse, E.J. Manseau, K. Tognazzi, C.A. Perruzzi, H.F. Dvorak, and D.R. Senger. 1994. Osteopontin expression and distribution in human carcinomas. Am. J. Pathol. 145:610-623.
15. Singh, R.P., R. Patarca, J. Schwartz, P. Singh, and H. Cantor. 1990. Definition of a specific interaction between the early $\mathrm{T}$ lymphocyte activation 1 (Eta-1) protein and murine macrophages in vitro and its effect upon macrophages in vivo. J. Exp. Med. 171:1931-1942.

16. Murry, C.E., C.M. Giachelli, S.M. Schwartz, and R. Vracko. 1994. Macrophages express osteopontin during repair of myocardial necrosis. Am. J. Pathol. 145:1450-1462.

17. Leibovich, S.J., and R. Ross. 1975. The role of the macrophage in wound repair: a study with hydrocortisone and anti-macrophage serum. Am. J. Pathol. 78:71-91.

18. Portera, C.A., E.J. Love, L. Memore, L. Zhang, A. Müller, W. Browder, and D.L. Williams. 1997. Effect of macrophage stimulation on collagen biosynthesis in the healing wound. Am. Surg. 63:125-130.

19. Giachelli, C.M., S.M. Schwartz, and L. Liaw. 1995. Molecular and cellular biology of osteopontin: potential role in cardiovascular disease. Trends Cardiovasc. Med. 5:88-95.

20. Giachelli, C.M., R. Pichler, D. Lombardi, D.T. Denhardt, C.E. Alpers, S.M. Schwartz, and R.J. Johnson. 1994. Osteopontin expression in angiotensin II-induced tubulointerstitial nephritis. Kidney Int. 45:515-524.

21. Kohri, K., S. Nomura, and Y. Kitamura. 1993. Structure and expression of the mRNA encoding urinary stone protein (osteopontin). J. Biol. Chem. 15: $180-184$.

22. Tybulewicz, V.L.J., C.E. Crawford, P.K. Jackson, R.T. Bronson, and R.C. Mulligan. 1991. Neonatal lethality and lymphopenia in mice with a homozygous disruption of the c-abl proto-oncogene. Cell. 65:1153-1163.

23. Zhao, G.-Q., K. Deng, P.A. Labosky, L. Liaw, and B.L.M. Hogan. 1996. The gene encoding bone morphogenetic protein $8 \mathrm{~B}$ is required for the initiation and maintenance of spermatogenesis in the mouse. Genes Dev. 10:1657-1669.

24. Davisson, M.T. 1995. Genetic nomenclature guide (mouse). In Trends in Genetics Nomenclature Guide. A. Stewart, editor. Elsevier Trends Journals, Oxford. 35-38.

25. Liaw, L., M. Almeida, C.E. Hart, S.M. Schwartz, and C.M. Giachelli. 1994. Osteopontin promotes vascular cell adhesion and spreading and is chemotactic for smooth muscle cells in vitro. Circ. Res. 74:214-224.

26. Zhao, G.-Q., and B.L.M. Hogan. 1996. Evidence that mouse Bmp8a $(O p 2)$ and $B m p 8 b$ are duplicated genes that play a role in spermatogenesis and placental development. Mech. Dev. 57:159-168.

27. Birk, D.E., and R.L. Trelstad. 1984. Extracellular compartments in matrix morphogenesis: collagen fibril, bundle, and lamellar formation by corneal fibroblasts. J. Cell Biol. 99:2024-2033.

28. Craig, A.M., and D.T. Denhardt. 1991. The murine gene encoding secreted phosphoprotein 1 (osteopontin): promoter structure, activity, and induction in vivo by estrogen and progesterone. Gene (Amst.) 100:163-171.

29. Liaw, L., M.P. Skinner, E.W. Raines, R. Ross, D.A. Cheresh, S.M. Schwartz, and C.M. Giachelli. 1995. The adhesive and migratory effects of osteopontin are mediated via distinct cell surface integrins. Role of $\alpha \mathrm{v} \beta 3$ in smooth muscle cell migration to osteopontin in vitro. J. Clin. Invest. 95:713-724.

30. Rowe, L.B., J.H. Nadeau, R. Turner, W.N. Frankel, V.A. Letts, J.T. Eppig, M.S. Ko, S.J. Thurston, and E.H. Birkenmeier. 1994. Maps from two interspecific backcross DNA panels available as a community genetic mapping resource. Mamm. Genome. 5:253-274.

31. Segre, J.A., J.L. Nemhauser, B.A. Taylor, J.H. Nadeau, and E.S. Lander. 1995. Positional cloning of the nude locus: genetic, physical, and transcription maps of the region and mutations in the mouse and rat. Genomics. 28: $549-559$.

32. Fet, V., M.E. Dickinson, and B.L.M. Hogan. 1989. Localization of the mouse gene for secreted phosphoprotein 1 (Spp1) (2ar, osteopontin, bone sialoprotein1, 44-kDa bone phosphoprotein, tumor-secreted phosphoprotein) to chromosome 5, closely linked to Ric (Rickettsia resistance). Genomics. 5:375377 .

33. Hynes, R.O. 1996. Targeted mutations in cell adhesion genes: what have we learned from them? Dev. Biol. 180:402-412.

34. Lampe, M.A., R. Patarca, M.V. Iregui, and H. Cantor. 1991. Polyclonal B cell activation by the Eta-1 cytokine and the development of systemic autoimmune disease. J. Immunol. 147:2902-2906.

35. Shepherd, V.L., R. Abdolrasulnia, M. Garrett, and H.B. Cowan. 1990. Down-regulation of mannose receptor activity in macrophages after treatment with lipopolysaccharide and phorbol esters. J. Immunol. 145:1530-1536.

36. Noorman, F., E.A.M. Braat, M. Barrettbergshoeff, E. Barbe, A. Vanleeuwen, J. Lindeman, and D.C. Rijken. 1997. Monoclonal antibodies against the human mannose receptor as a specific marker in flow cytometry and immunohistochemistry for macrophages. J. Leukocyte Biol. 61:63-72.

37. McKee, M.D., and A. Nanci. 1996. Secretion of osteopontin by macrophages and its accumulation at tissue surfaces during wound healing in mineralized tissues: a potential requirement for macrophage adhesion and phagocytosis. Anat. Rec. 245:394-409.

38. Clore, J.N., I.K. Cohen, and R.F. Diegelmann. 1979. Quantitation of the collagen types I and III during wound healing in rat skin. Proc. Soc. Exp. Biol. Med. 161:337-340.

39. Liu, X., H. Wu, M. Byrne, S. Krane, and R. Jaenisch. 1997. Type III collagen is crucial for collagen I fibrillogenesis and for normal cardiovascular development. Proc. Natl. Acad. Sci. USA. 94:1852-1856. 
40. Toman, D., L. Garrett, T. Mascara, J. Bateman, and B. de Crombrugghe. 1993. Transgenic mice harboring a Lys $\rightarrow$ Met cross-linking mutation in type III collagen. Matrix. 13:50. (Abstr.)

41. Quaglino, D., Jr., D. Toman, B. de Crombrugghe, and J.M. Davidson. 1994. Transgenic mice expressing a col3a1 mutation at a crosslinking position exhibit structural alterations at sites of wound healing. Matrix Biol. 14:512. (Abstr.)

42. Birk, D.E., and R. Mayne. 1997. Localization of collagen types I, III and V during tendon development. Changes in collagen types I and III are correlated with changes in fibril diameter. Eur. J. Cell Biol. 72:352-361.

43. Birk, D.E., M.V. Nurminskaya, and E.I. Zycband. 1995. Collagen fibrillogenesis in situ: fibril segments undergo post-depositional modifications resulting in linear and lateral growth during matrix development. Dev. Dyn. 202:229243.

44. Birk, D.E., E.I. Zycband, S. Woodruff, D.A. Windelmann, and R.L. Trelstad. 1997. Collagen fibrillogenesis in situ: fibril segments become long fibrils as the developing tendon matures. Dev. Dyn. 208:291-298.

45. Iozzo, R.V. 1997. The family of small leucine-rich proteoglycans: key regulators of matrix assembly and cellular growth. Crit. Rev. Biochem. Mol. Biol. 32:141-174
46. Danielson, K.G., H. Baribault, D.F. Holmes, H. Graham, K.E. Kadler, and R.V. Iozzo. 1997. Targeted disruption of decorin leads to abnormal collagen fibril morphology and skin fragility. J. Cell Biol. 136:729-743.

47. Okada, A., C. Tomasetto, Y. Lutz, J.P. Bellocq, M.C. Rio, and P. Bassett. 1997. Expression of matrix metalloproteinases during rat skin wound healing: evidence that membrane type-1 matrix metalloproteinase is a stromal activator of pro-gelatinase A. J. Cell Biol. 137:67-77.

48. Chen, Y., B.S. Bal, and J.P. Gorski. 1992. Calcium and collagen binding properties of osteopontin, bone sialoprotein, and bone acidic glycoprotein-75 from bone. J. Biol. Chem. 267:24871-24878.

49. Butler, W.T. 1995. Structural and functional domains of osteopontin. Ann. NY Acad. Sci. 760:6-11.

50. Mukherjee, B.B., M. Nemir, S. Beninati, E. Cordella-Miele, K. Singh, I. Chackalaparampil, V. Shanmugan, M.W. DeVouge, and A.B. Mukherjee. 1995. Interaction of osteopontin with fibronectin and other extracellular matrix molecules. Ann. NY Acad. Sci. 760:201-212.

51. McKee, M.D., S. Zalzal, and A. Nanci. 1996. Extracellular matrix in tooth cementum and mantle dentin: localization of osteopontin and other noncollagenous proteins, plasma proteins, and glycoconjugates by electron microscopy. Anat. Rec. 245:293-312. 